\title{
Türkiye’nin 2007-2013 Dönemi Avrupa Birliği Kırsal Kalkınma (IPARD) Fonlarını Kullanımı Üzerine Bir Araştırma
}

Yusuf ÖZTÜRKCI்

Tarım ve Kırsal Kalkınmayı Destekleme Kurumu, Van, Türkiye

\section{Özet}

Avrupa Birliği (AB) aday ve potansiyel aday ülkelere sağlamış olduğu mali yardımları Katılım Öncesi Mali Yardım Aracı (InsturumentforPre-accession Assistance-IPA) olarak tek çatı altında toplamıştır. Türkiye, aday ülke statüsünde bulunduğundan IPA çatısı altında bulunan beş bileşenden de mali kaynak sağlamaktadır. Bu kapsamda ülkemiz beşinci bileşen olan Kırsal kalkınma (Rural Development) bileşeninden (IPARD) yararlanmaya başlamıştır. Türkiye için tahsis edilen Kırsal Kalkınma (IPARD) fonlarının kullanımını sağlamak üzere, Tarım ve Kırsal Kalkınmayı Destekleme Kurumu (TKDK) 2007 yılında 5648 sayılı kanunla kurulmuştur. Tahsis edilen fonların kullanımı için kurulan TKDK'nın fonları kullanabilmesi için AB'den yetki devri alma şartı getirilmiş ve Türkiye tarafından yetki devri 2011 yılında alınmıştır. TKDK ilk aşamada 20 il koordinatörlüğü, ikinci aşamada 22 il koordinatörlügü olmak üzere 42 ilde faaliyetlerini sürdürmektedirler. TKDK program dahilinde hayvancılık kapsamında et (kırmızı ve kanatlı)ve süt üretimi gıda işleme kapsamında et ve et ürünleri, süt ve süt ürünleri, su ürünleri, meyve sebze işleme ve pazarlama, kırsal alanların kalkınmasına yönelik arıcılık, tıbbi aromatik ve süs bitkisi yetiştiriciliği, zanaatkarlık, yerel tarım gıda ürünlerinin üretimi işlenmesi ve pazarlanması, kırsal turizm, kültür balıkçılığ gibi yatırımları desteklemektedir. Programın ilk yedi yıllık uygulama döneminde (2007-2013) 10.693 proje ile sözleşme imzalanarak yatırıma dönüştürülmüş, tahsis edilen 854,6 milyon avroluk bütçenin \% 99.52 'sini kullandırmış, program süresince yaklaşık 6.7 milyar TL'lik yatırıma ve 3.15 milyar TL'lik hibe desteği sağlanmıştır. Desteklenen yatırımlar sonucunda 57 bin yeni istihdam oluşturulmuştur. Proje başvurusunda bulunan kişi ya da temsilcilerinin kadın ya da genç olmasına öncelik verilmesinden dolayı 40 yaş altı 4.572 yatırımcı ve 1.055 kadın yatırımcı desteklenmiştir. $\mathrm{Bu}$ çalışmada Türkiye'de IPARD fonları ile desteklenen yatırımlar hakkında bir inceleme yapılmış ve konu hakkında bilgilendirme amaçlanmıştır.

Anahtar Kelimeler: Kırsal Kalkınma, IPA, IPARD, TKDK 


\title{
A Study About Using Of Ipard Funds Of Eu Between Years Of 2007 - 2013 By Turkey
}

\begin{abstract}
European Union (EU) unified all of the financial aid for the candidate and potential candidate countries into the single framework of that named as pre-accession assistance (IPA) Due to Turkey's candidate country status it is beneficent of all IPA components. One of these components is the IPA-5 component (also naming as IPARD) is about agricultural and rural development funds. To manage these funds in Turkey, Agriculture and Rural Development Support Institution (ARDSI) has been developed with the law nr: 5648. Before the implementation of the IPA-5 program conferral for this authorization was required. In 2011 this process has been completed. ARDSI has 42 provincial unit with the organized as phase 1 (20 cities) and phase 2 (22 cities). Within the scope of the program meat (red and poultry), dairy production, food processing, meat, and meat products, milk and dairy products, aquaculture, processing and marketing of vegetables and fruit, beekeeping, invest for rural tourism of rural areas, growing medicinal aromatic plants has been supported. At the first 7, during the implementation IPA-5 of program (2007-2013) 10.693 investment project has been supported. $99.52 \%$ of the $854 \mathrm{~m}$ Euros budget has been disbursed. In other words, by the $3.15 \mathrm{~b}$ grants, the co-funded investment project with a $6.7 \mathrm{~b}$ amount was realized. This resulted in 57.000 new employment. Due to positive discrimination for women and young entrepreneurs, the 1.055 woman and 4.572 entrepreneurs under age 40 have been supported. In this study, this invests has been analyzed.
\end{abstract}

Keywords: Rural Development, IPA, IPARD, ARDSI

\section{GÍRIŞ}

Türkiye, batı ile entegrasyonu güçlendirmek için 1947 yılında temelleri atılan Avrupa Ekonomik Topluluğuna (AET) ortak üyelik için 1959 yılında başvuruda bulunarak yarım asrı aşkın süredir devam eden üyelik sürecini başlatmıştır. Türkiye'nin ortak üyelik başvurusu 1963 yılında imzalanan Ankara Anlaşması ile kabul edilmiştir. Yapılan anlaşma çerçevesinde tam üyelik sürecine kadar üç aşamalı (Hazırlık, Geçiş, Son Dönem) bir yöntem uygulanması 


\section{ISSN2777-7238 |ISPEC Journal of Agricultural Sciences}

öngörülmüştür. Hazırlık aşaması 1964 yılında yürürlüğe giren Ankara Anlaşması ile başlamış, 1970 yılında imzalanan Katma Protokol ile sonlanmış ikinci aşamaya geçilmiştir. Geçiş dönemi olarak adlandırılan ikinci aşama, Katma protokol ile başlamış 1995 yılında imzalanan Gümrük Birliği Anlaşması ile sona ermiştir. Gümrük Birliği Anlaşmasının imzalanması ile Türkiye’nin Avrupa Birliği'ne (AB) tam üyelikle sonuçlanması ile öngörülen Son Dönem aşaması başlamıştır (Demirkıran ve ark. 2010).

Son Dönem aşamasının başlamasıyla Türkiye- AB arasında üyelikle alakalı yoğun pazarlıklar uzun süre devam etmiştir. Özellikle 1997 Helsinki Zirvesi’nde Türkiye’ye diğer aday ülkelerden farklı özel siyasi koşulların öne sürülmesi ilişkilerdeki soğukluğa neden olmuştur. 1998 yılında yapılan Cardiff Zirvesi'nde Türkiye'nin üyelik konumunda ilerleme kaydedilmesi (Kösecik ve Yıldırım 2001) gerilen ortamı yumuşatmıştır. Türkiye'nin AB'ne uzun süre devam eden tam üye adaylığı süreci, 1999 yılında Helsinki Zirvesi’nde diğer aday ülkelerle eşit kriter ve şartlarda değerlendirmesi kararı oybirliği ile kabul edilmiştir (Özcan, 2011). 1950'lerden süregelen Türkiye- AB ilişkilerinin en önemli ve tarihi kararı, 3 Ekim 2005'te Brüksel Zirvesi sonucunda elde edilen AB ile müzakerelere başlama kararının alınmasıdır (Özer 2007).

$\mathrm{AB}$, aday ülkeleri belli alanlarda gelişim ve topluluk standartlarının yakalanması amacı ile mali destek programları desteklemektedir. Türkiye, aday ülkelere uygulanan PHARE, ISPA VE SAPARD gibi mali yardım araçlarından yararlanma talebinde bulunmuş, program bütçelerinin kesinleşmiş ve kapanmış olması sebebiyle farklı programlardan destek taahhüdü verilmiştir. Buna yönelik olarak 2001 yılında tüm bu mali programların birleştirici nitelikte olan Tek Çerçeve ile mali destek sürecinin sürdürülmesi kararı alınmıştır. Bu çalışmada IPA fonları hakkında genel bir bilgilendirme ve Kırsal Kalkınma bileşeni olan IPARD fonlarının Türkiye tarafından kullanım durumunun değerlendirilmesi amaçlanmıştır.

\section{KAVRAMSAL ÇERÇEVE}

\section{Insturument For Pre-Accession Assistance (IPA)}

Tek Çerçeve yaklaşımının uygulanmasına yönelik Konsey, Katılım Öncesi Mali Yardım Aracı'nın (Insturument for Pre-accession Assistance-IPA) kurulmasını öngören IPA Konsey Tüzüğünü (EC No: 1085/2006) kabul etmiştir. Kabul edilen bu yeni tüzük beraberinde önemli düzenlemeler getirmiştir. Daha önce imzalanan mali anlaşmalarla uygulanmakta olan bu mali destek programları daha bütüncül bir yaklaşımla ele alınmaya başlanmıştır. Mali programları tek bir çatı altında birleştirme süreci bu kaynakların daha etkin ve verimli kullanılmasını Year 3/2019, Volume-3, Issue-1 | https://ispecjournal.com 


\section{ISSN2717-7238 ISPEC Jaurnal of Agricultural Sciences}

sağlamış bununla beraber planlama, kontrol ve denetim mekanizmalarının da daha anlaşılır ve şeffaf hale gelmesinin önünü açmıştır (Toprak 2010).

2007 y1lında Komisyon tarafından kabul edilerek ilan edilen Birliğin Stratejik Planlama Dokümanı ile 2007-2013 dönemini kapsayan IPA Bütçesi kesinlik kazanmıştır. Buna göre aday ve potansiyel aday ülkelere ayrılan toplam IPA bütçesi 9.9 milyar avrodur. Tahsis edilen bütçenin nüfus ve yüz ölçüm gibi kriterler dikkate alınarak yaklaşık yarısı (\%48) 4.8 milyar avro Türkiye'ye ayrılmıştır (Anonim 2018).

Çizelge 1. 2007-2013 IPA Dönemi AB Mali Yardımının Aday ve Potansiyel Aday Ülkelere Göre Dağılımı (https://www.ab.gov.tr/5.html )

\begin{tabular}{|c|c|c|c|c|c|c|}
\hline \multirow[b]{2}{*}{ Hirvatistan* } & \multirow{2}{*}{$\begin{array}{c}\begin{array}{c}\text { Yüzölçümüi } \\
\left(\mathbf{k m}^{2}\right)\end{array} \\
56594\end{array}$} & \multirow{2}{*}{$\begin{array}{c}\text { Avro/km } \\
17634\end{array}$} & \multirow{2}{*}{$\begin{array}{c}\text { Nüfus-2006 } \\
4443000\end{array}$} & \multicolumn{2}{|c|}{$\begin{array}{l}\text { Toplam (Milyon } \\
\text { Avro/Kişi Avro) } \\
\end{array}$} & \multirow{2}{*}{$\begin{array}{c}\begin{array}{c}\text { Oran } \\
(\%)\end{array} \\
10.0\end{array}$} \\
\hline & & & & 224.6 & 998 & \\
\hline Makedonya & 25713 & 23918 & 2039000 & 301.6 & 615 & $6.2 \%$ \\
\hline Türkiye & 783562 & 6119 & 72520000 & 66.1 & 4795 & 48.2 \\
\hline Arnavutluk & 2875 & 206957 & 3149000 & 188.9 & 595 & 6.0 \\
\hline Bosna Hersek & 1209 & 12810 & 3843000 & 170.7 & 656 & 6.6 \\
\hline Karadağ & 13812 & 17087 & 624000 & 378.2 & 236 & 2.4 \\
\hline Sirbistan & 77474 & 17890 & 7425000 & 186.7 & 1386 & 13.9 \\
\hline Kosova & 10887 & 58326 & 2070000 & 306.8 & 635 & 6.4 \\
\hline İzlanda** & & & & & 30 & 0.3 \\
\hline \multicolumn{7}{|c|}{$\begin{array}{l}\text { *Hırvatistan, Temmuz } 2013 \text { tarihinden itibaren AB'ye üye olmuştur. } \\
\text { **İzlanda yardımlardan } 2011 \text { yılında faydalanmaya başlamıştır. }\end{array}$} \\
\hline \multirow{2}{*}{\multicolumn{7}{|c|}{$\begin{array}{l}\text { Mali destekleri tek çatı altında toplayan IPA temel olarak } 5 \text { ana bileşen altında planlanmıştır. } \\
2006 \text { yılında kabul edilen IPA Tüzüğü’ne göre mali kaynaklar bu bileşenler altında } \\
\text { programlanarak kullandırılacaktır. Bu bileşenler (Anonim 2018); }\end{array}$}} \\
\hline & & & & & & \\
\hline \multicolumn{7}{|c|}{ I. Geçiş Dönemi Desteği ve Kurumsal Yapılanma } \\
\hline \multicolumn{7}{|c|}{ II. Bölgesel ve Sınır Ötesi İşbirliği } \\
\hline \multicolumn{7}{|c|}{ III. Bölgesel Kalkınma } \\
\hline IV. İnsan Ka & aklarının Ge & irilmesi & & & & \\
\hline
\end{tabular}




\section{Kırsal Kalkınma}

Bu bileşenler içinde Geçiş Dönemi Desteği ve Kurumsal Yapılanma bileşeni ile Bölgesel ve Sınır Ötesi İşbirliği bileşenlerinden hem aday ülkeler hem de potansiyel aday ülkeler yararlanmakta iken Bölgesel Kalkınma, İnsan Kaynaklarının Geliştirilmesi ve Kırsal Kalkınma Bileşenlerinden yalnızca aday ülkeler yararlanabilmektedir. Dolayısıyla Türkiye aday ülke statüsü nedeniyle IPA'nın tüm bileşenlerinden fon kullanabilmektedir.

Türkiye'ye tahsis edilen 4.8 milyar avro IPA (2007-2013) bütçesi beş bileşen için aşağıdaki şekilde tahsis edilmiştir (Anonim 2018).

Çizelge 2. IPA (2007-2013) Türkiye Yı1lara Göre Mali Yardım Miktarları (milyon avro)

\begin{tabular}{|c|c|c|c|c|c|c|c|c|}
\hline Bileșenler & 2007 & 2008 & 2009 & 2010 & 2011 & 2012 & 2013 & Toplam \\
\hline $\begin{array}{l}\text { I. Geçiş Dönemi Desteği ve } \\
\text { Kurumsal Yapılanma }\end{array}$ & 256.7 & 256.1 & 239.6 & 217.8 & 231.3 & 227.5 & 238.5 & 1667.5 \\
\hline II. Sınır Ötesi İşbirliği & 2.1 & 2.9 & 3.0 & 3.1 & 5.1 & 2.2 & 2.2 & 20.6 \\
\hline III. Bölgesel Kalkınma & 167.5 & 173.8 & 182.7 & 238.1 & 293.4 & 356.1 & 366.9 & 1778.4 \\
\hline $\begin{array}{l}\text { IV. İnsan Kaynaklarının } \\
\text { Geliştirilmesi }\end{array}$ & 50.2 & 52.9 & 55.6 & 63.4 & 77.6 & 83.2 & 91.2 & 474.1 \\
\hline V. Kırsal Kalkınma & 20.7 & 53.0 & 85.5 & 131.3 & 172.5 & 187.4 & 204.2 & 854.6 \\
\hline Toplam & 497.2 & 538.7 & 566.4 & 653.7 & 779.9 & 856.3 & 903.0 & 4795.2 \\
\hline
\end{tabular}

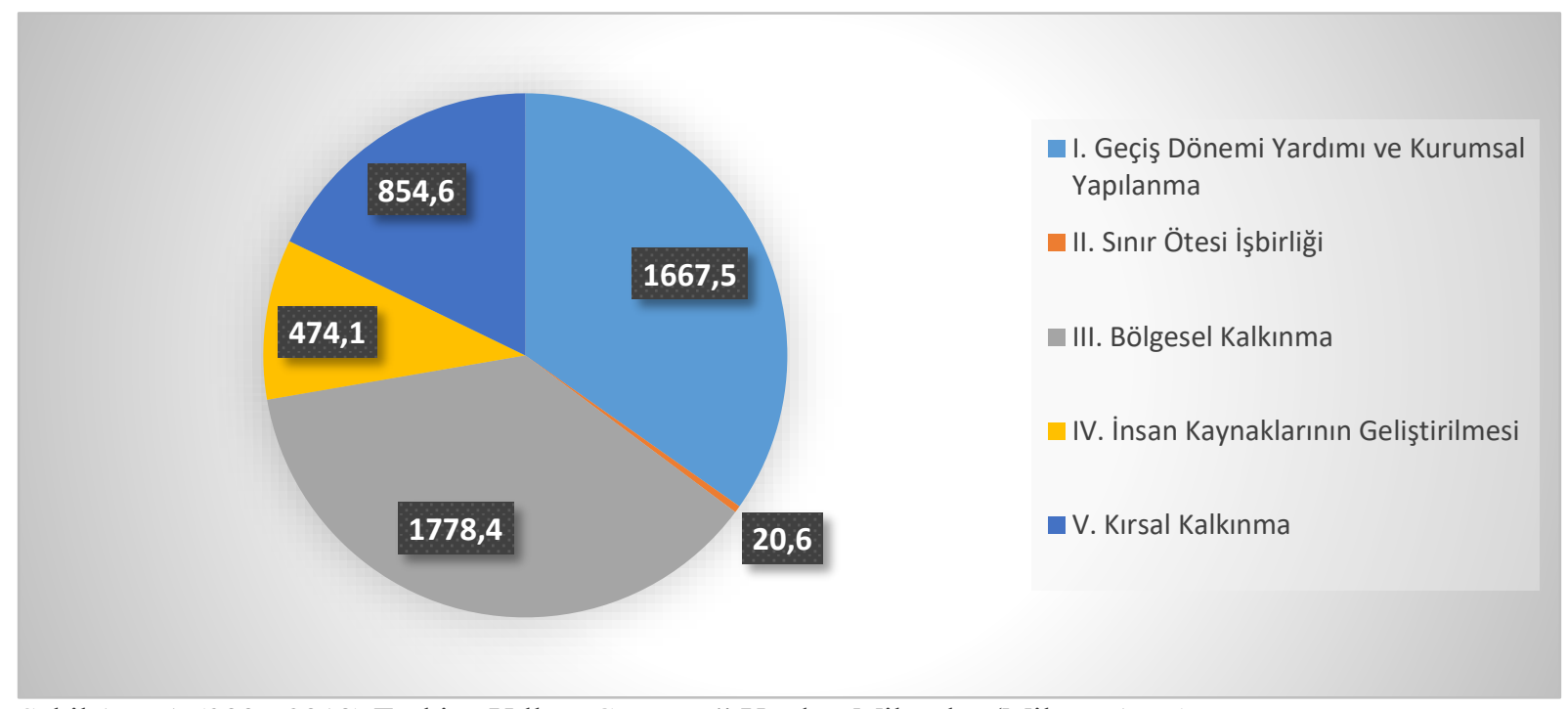

Şekil 1: IPA (2007-2013) Türkiye Yıllara Göre Mali Yardım Miktarları(Milyon Avro) 


\section{ISSN2777-7238 | ISPEC Journal of Agricultural Sciences}

IPA-I Geçiş Dönemi Desteği ve Kurumsal Yapılanma: IPA'nın önemli bileşenlerinden biridir ve bu bileşenin faydalanıcıları kamu kurum ve kuruluşlarıdır. Bileşen kapsamında kamu yönetimi reformu, müktesebat uyumu, temel haklar ve sivil toplumun gelişimi, içişleri, adalet, eğitim ve sağlık sitemi reformu, yolsuzlukla mücadele gibi alanlar proje yoluyla finanse edilmektedir. Ayrıca bu bileşen altında AB-TR sivil toplum diyaloğunun geliştirilmesi amaçlanmıştır. Bu amaçla Dış İşleri Bakanlığı AB başkanlığg tarafından yürütülen ve 2006'dan beri yüzlerce sivil toplum kuruluşu projelerle desteklenerek programa dahil olmuştur (Anonim 2018).

IPA-II Sınır Ötesi İşbirliği: Ulusal otorite olarak Dış İşleri Bakanlığı AB başkanlığı görev almaktadır. Bu bileşende Bulgaristan-Türkiye IPA sınır ötesi işbirliği ve Avrupa komşuluk ve ortaklık aracı (ENPI) Karadeniz havzasında sınır ötesi işbirliği programlarına katılım sağlamaktadır. Programın öncelikleri çevrenin korunması, sosyal ve ekonomik kalkınma, eğitim ve kültür alanındaki gelişim için sınır ötesi ortaklıkların oluşturulması ve tecrübe aktarımı gibi konulardır. Program Türkiye'de Bulgaristan sınırı olan Kırklareli ve Edirne illeri ile Karadeniz havzası programı kapsamında Karadeniz'in 25 ve İstanbul İllerini kapsamaktadır. Bileşenler arasında en düşük fon bu bileşen için tahsis edilmiştir (20.6 milyon Avro).

IPA-III. Bölgesel Kalkınma: IPA bileşenleri arasındaki en yüksek fon tahsisi bu bileşen için yapılmış ve genel olarak yüksek bütçeli yatırımlar finanse edilmektedir. Bileşenin temel amacı aday ülkeyi üyelik sonrası yapısal fonlara hazırlamaktır. Türkiye için bu bileşenden Çevre ve Şehircilik, Ulaştırma ve Altyapı ve Sanayii ve Teknoloji Bakanlıkları sorumludur.

IPA-IV. İnsan Kaynaklarının Geliştirilmesi: Bileşen, Aile Çalışma ve Sosyal Hizmetler Bakanlığı tarafından koordine edilmektedir. Avrupa sosyal fonuna uyum hazırlıkları alanında destek vermektedir. Bileşenin temel amacı aday ülkeyi, birlik uyum politikalarının uygulanmasina hazırlamaktır.

IPA-V Kırsal Kalkınma: IPA'nın beşinci bileşeni olan Kırsal Kalkınma IPARD olarak adlandırılmaktadır. Bileşenden sorumlu bakanlık Tarım ve Orman Bakanlığı'dır. Bileşen kapsamında tarım, gıda, balıkçılık alanlarında ve kırsal alanların kalkınmasına yönelik alternatif alanlarda faaliyet gösteren/gösterecek gerçek ve tüzel kişilere proje aracılığı ile finansman desteği sağlanması planlanmaktadır. Türkiye'de IPARD Ajansı olarak Tarım ve Kırsal Kalkınmayı Destekleme Kurumu (TKDK) kurulmuş ve 42 ili kapsayacak şekilde faaliyetlerini sürdürmektedir. 


\section{ISSN2717-7238 ISPEC Jaurnal of Agricultural Sciences}

\section{IPARD ve TKDK}

Türkiye'nin Avrupa Birliği (AB) adaylık sürecinde yürütülen müzakerelerin 11. başlığı olan Kırsal Kalkınma faslı; AB ortak tarım politikası (OTP) ve kırsal kalkınma politikası müktesebatını içermektedir. AB'ye katılım öncesinde, AB mevzuatına uyum sağlanması ve uyumlaştırılan mevzuatın uygulanması için gerekli idari ve kurumsal altyapının oluşturulması gerekmektedir. Bu kapsamda, kırsal kalkınma faslının müzakerelere açılabilmesi için istenen kriterlerden biri AB gereklerine uygun, akredite edilmiş bir IPARD Ajansı'nın kurulmasıdır. Bu doğrultuda; IPARD fonlarını kullandırmak üzere, Tarım ve Kırsal Kalkınmayı Destekleme Kurumu (TKDK) 18 Mayıs 2007'de resmi gazetede yayımlanarak; 5648 sayılı kanunla, Kamu tüzel kişiliğine haiz, idari ve mali özerkliğe sahip, özel bütçeli ve Tarım ve Orman Bakanlığı'nın ilgili kuruluşu olarak kurulmuştur(resmi gazete). Kuruluşu müteakip hızlı bir şekilde akreditasyon ve yetki devri çalışmalarına başlamıştır yoğun prosedürel ve altyapı çalışmaları neticesinde 29 Ağustos 2011 'de AB komisyonundan fon dağıtma yeterliliğini sağlayarak yetki devri almıştır. Burada anılan yetki devri Avrupa Birliği ile ilgili fonların dağıtılması sürecinde TKDK'nın, IPA'nın Türkiye'de faaliyet gösteren AB Delegasyonunu ile bütünleşik yapısına göre daha özerk bir yapı içerisinde proje kabulü ve ödemesi gibi süreçlerle ilgili yetkilerin devridir. TKDK ilk aşamada 20 il (Afyonkarahisar, Amasya, Balıkesir, Çorum, Diyarbakır, Erzurum, Hatay, Isparta, Kahramanmaraş, Kars, Konya, Malatya, Ordu, Samsun, Sivas, Şanlıurfa, Tokat, Trabzon, Van, Yozgat) için yetki devri alarak projeleri kabul etmiş, Eylül 2012' de programın ikinci uygulama illeri olarak 22 il de (Ağrı, Aksaray, Ankara, Ardahan, Aydın, Burdur, Bursa, Çanakkale, Çankırı, Denizli, Elazığ, Erzincan, Giresun, Karaman, Kastamonu, Kütahya, Manisa, Mardin, Mersin, Muş, Nevşehir, Uşak) ikinci aşamada yetki devri alarak fon kullanımına başlamıştır(TKDK 2018a)

Yedi yıllık hazırlanarak kabul edilen IPARD I programı 2007-2013 yılarını, IPARD II programı ise 2014-2020 yıllarını kapsamaktadır. IPARD I programının kapanışı 2016 yılının sonunda yapılmıştır. Programın temelini aday ülkenin ihtiyaçları ve AB'ye üyelik sürecinde ilgili alanları AB standartlarına ulaştırma oluşturmaktadır. Bu bağlamda program için belli öncelik eksenleri belirlenmiştir (Bilici 2010). 
Çizelge 3. IPARD Öncelik Eksenleri ve Tedbirleri

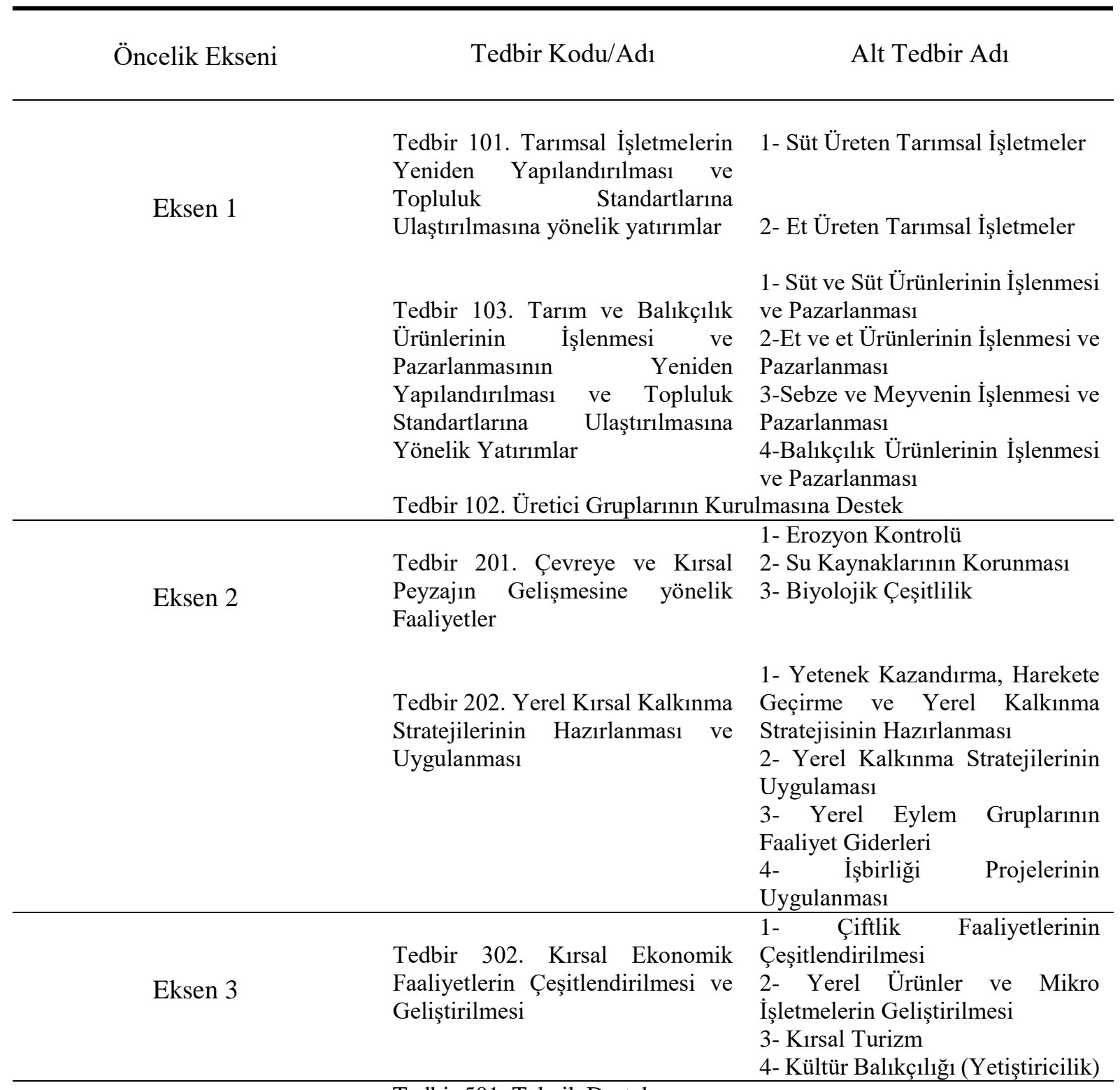

Tedbir 501. Teknik Destek

Ortak finansman modelinin uygulandığg programda uygun yatırımların tedbire göre değişmekle birlikte bir bölümü yatırımcı tarafından bir bölümü de kamu katkısı olarak TKDK tarafından finanse edilmektedir. Kamu katkısı olarak ifade edilen IPARD (TKDK) desteğinin \% $\%{ }^{\prime}$ ’ AB tarafindan \%25'i ise Türkiye Cumhuriyeti katkısı olarak yatırımcilara hibe olarak verilmektedir. IPARD I programında 3 tedbir başlı̆̆ 1 altında proje çağrısına çıkılarak fon dağıtımı gerçekleştirilmiştir. Proje çağrısına çıkılan tedbirler 101, 103 ve 302 tedbirleridir. 101 tedbirinde hibe oranı başvuru sahibinin yaşına ve yatırımın yapıldı̆̆ Year 3/ 2019, Volume-3, Issue-1 | https://ispecjournal.com 


\section{ISSN2717-7238 ISPEC Jaurnal of Agricultural Sciences}

arasında değişirken, 103 ve 302 tedbirlerinde $\% 50$ olarak sabit bir oranda hibe desteğinde bulunulmuştur. Desteklenen yatırımlar verilen hibenin dışında, TKDK tarafından uygun kabul edilen harcamalar için vergilerden muaf tutularak dolaylı olarak desteklenmiştir.

TKDK yetki devri alınmasını müteakip yaklaşık 4-4.5 yıllık süreçte yoğun bir şekilde proje çağrılarına çıkmış ve 15 proje çağrı dönemi kapsamında fon kullanımını gerçekleştirmiştir(TKDK 2018b).

Çizelge 4. IPARD Başvuru Çağrı Tarihleri (tkdk.gov.tr)

\begin{tabular}{|c|c|c|c|}
\hline $\begin{array}{c}\text { Çağrı } \\
\text { Dönemi }\end{array}$ & Çağrı İlanı Tarihi & $\begin{array}{c}\text { Toplam Destek } \\
\text { Bütçesi (€) } \\
(\mathrm{AB}+\mathrm{TC}) \\
\end{array}$ & Başvuru Kabul Tarihleri \\
\hline 1. Çağrı & 1 Temmuz 2011 & $91388000.00 €$ & 1 -26 Ağustos 2011 \\
\hline 2. Çağrı & 4 Temmuz 2011 & $100894560.00 €$ & 5 Eylül-6 Ekim 2011 \\
\hline 3. Çağrı & 17 Ekim 2011 & $106020000.00 €$ & 19 Aralık 2011- 16 Ocak 2012 \\
\hline 4. Çağrı & 19 Aralık 2011 & $74774800.00 €$ & 1-29 Şubat 2012 \\
\hline 5. Çağrı & 1 Mart 2012 & $164737344.00 €$ & 15 Mart-11 Haziran 2012 \\
\hline 6. Çağrı & 15 Mayıs 2012 & $124430542.46 €$ & 18 Haziran-16 Temmuz 2012 \\
\hline 7. Çağrı & 24 Ağustos 2012 & $120267484.77 €$ & 1-31 Ekim 2012 \\
\hline 8. Çağrı & 23 Kasım 2012 & $295134385.00 €$ & 17 Aralık 2012-15 Ocak 2013 \\
\hline 9. Çağrı & 23 Ocak 2013 & $236482590.67 €$ & 15 Şubat- 26 Mart 2013 \\
\hline 10. Çağrı & 19 Nisan 2013 & $195910609.40 €$ & 26 Nisan- 06 Mayis 2013 \\
\hline 11. Çağrı & 26 Ağustos 2013 & $512713338.12 €$ & 30 Eylül - 8 Kasım 2013 \\
\hline 12.Çağrı & 15 Ocak 2014 & $488772128.00 €$ & 10 Şubat-21 Mart 2013 \\
\hline 13.Çağrı & 10 Kasım 2014 & $187826012.00 €$ & 12 Ocak-10 Şubat 2015 \\
\hline 14.Çağrı & 17 Nisan 2015 & $121000000.00 €$ & 11 Mayıs-10 Haziran 2015 \\
\hline 15.Çağrı & 8 Ekim 2015 & $37500000.00 €$ & 19 Ekim-04 Kasım 2015 \\
\hline
\end{tabular}




\section{ISSN2717-7238 $\mid$ ISPEC Jaurnal of Agricultural Sciences}

TKDK tarafından çıkılan 15 proje çağrısı; 101, 103 ve 302 olarak kodlanan tedbirlere yönelik çağrılardır. IPARD programı kapsamında yatırımlarda belli harcamalar uygun kabul edilirken bazı harcamalarda uygun olarak değerlendirilmeyerek başvurucu tarafından finanse edilmesi kararlaştırılmıştır. Uygun olarak kabul edilen harcama alanları dört başlık altında toplanmıştır. Yapım işleri, makine ekipman (Bilgi sistemleri dahil) alımı, genel hizmetler (Proje hazırlama ve Danışmanlık Hizmetleri) ve görünürlük harcaması uygun olarak kabul edilerek destek kapsamında değerlendirilmiştir. Canlı hayvan alımı, ikinci el makine ekipman alımı, arazi satın alınması, kira, personel giderleri, sigorta ve harç gibi giderlerde uygun olmayan harcama olarak değerlendirilmiştir. Ayrıca desteklenecek yatırımlar için karlılık ve sürdürülebilirlik faktörleri göz önüne alınarak belli kapasite kriterleri belirlenmiştir. 302 tedbiri için mikro, 101 ve 103 için mikro, küçük ve orta ölçekli olma kriteri istenmiştir. Bu kriterlerin yanı sıra 302 tedbirinin kırsal alanda olması ve 103 tedbiri için kurulacak yeni işletmenin ilde kapasite fazlası oluşturmadığını kanıtlaması gerekmektedir. Program kapsamında 101, 103 ve 302 tedbirleri kapsamında ve aşağıda yer alan kapasite kriterleri doğrultusunda kurulacak yeni işletme ve mevcut işletmelerin modernizasyon projeleri kabul edilmektedir.

Tedbir 101 olarak kodlandırılan, Tarımsal İşletmelerin Yeniden Yapılandırılması ve Topluluk Standartlarına Ulaştırılmasına yönelik yatırımlar sektörü kapsamında küçükbaş ve büyükbaş süt üreten tarımsal işletmeler desteklenmektedir. Desteklenen yatırımlarda büyükbaş için 10120 süt ineği, küçükbaş işletmelerinde 50-500 koyun/keçi arasındaki işletmeler uygun olarak kabul edilmektedir. Et üreten tarımsal işletmeler alt tedbiri kapsamında beyaz ve kırmızı et üreten tarımsal işletmeler desteklenmektedir. Kırmızı et üretiminde büyükbaş için 30-250 arası sığır, küçükbaşta ise (koyun/keçi) 100-500 adet arasındaki işletmeler, beyaz et (kanatlı) üretiminde 1.000-8.000 adet arasındaki hindi ve 5 000-50 000 adet arasındaki broyler işletmeleri uygun yatırımlar olarak değerlendirilmektedir. Tarım ve Balıkçılık Ürünlerinin İşlenmesi ve Pazarlanmasının Yeniden Yapılandırılması ve Topluluk Standartlarına Ulaştırılmasına Yönelik Yatırımlar sektörü olan 103 tedbiri ise üretilen gıda ve hayvansal ürünlerin işlenmesi ve pazarlanmasını kapsayan yatırımlar desteklenmektedir. Bu kapsamda süt ürünlerinin işlenmesi ve pazarlanması alt tedbirinde günlük kapasitesi 10-70 ton arasındaki süt işleme (süt, yoğurt, ayran, peynir vb.) tesisleri ve günlük en fazla 70 ton kapasiteli süt toplama merkezleri destek kapsamında yer almıştır. Et ve et ürünlerinin işlenmesi ve pazarlanması sektörü kapsamında kırmızı ve beyaz (kanatlı eti) et işleme, parçalama ve kesimhaneler desteklenmektedir. Kırmızı ve beyaz et işleme ve parçalama tesislerinde kapasite 0.5-5 ton Year 3/ 2019, Volume-3, Issue-1 | https://ispecjournal.com 


\section{ISSN2777-7238 |ISPEC Journal of Agricultural Sciences}

aralığında olmalı, kesimhane kurulması ya da modernizasyonu durumunda kırmızı ette büyükbaş için günlük 30-500 baş, küçükbaş için günlük 50-4 000 baş kapasiteli, beyaz ette tavuk için saatte 1 000-5 000 adet, hindi için saatte 100-1 000 adet kapasiteye sahip olmalıdır. Sebze ve Meyvenin İşlenmesi ve Pazarlanması alt tedbirinde öncelikli amaç hasat sonrası kayıpların azaltılması olduğu için üründe fiziksel ve kimyasal bir değişim istenmemektedir. $\mathrm{Bu}$ kapsamda sebze ve meyvenin depolanması için soğuk hava depoları, paketleme, tasnifleme, kurutma ve ürün taşıma ekipmanları gibi yatırımlar desteklenmektedir. Soğuk hava deposu için üst kapasite $10000 \mathrm{~m}^{3}$ sınırını aşmamalıdır. Balıkçılık Ürünlerinin İşlenmesi ve Pazarlanması sektöründe ise su ürünleri ve kültür balıkçılığg ile ilgili yatırımlar desteklenmektedir. İşletmenin yıllık kapasitesi 100-2 000 ton arasında olmalıdır. Tedbir 302. Kırsal Ekonomik Faaliyetlerin Çeşitlendirilmesi ve Geliştirilmesi kapsamında 4 alt tedbir başlığında destek sunulmaktadır. Tedbir kapsamında desteklenecek yatırımların kırsal alanda yer alması gerekmektedir. Çiftlik faaliyetlerinin çeşitlendirilmesi alt tedbirinde arıcılık, süs bitkileri ve tıbbi aromatik bitki yetiştiriciliği desteklenmektedir. Arıcılık için kovan sayısı kapasitesi 50-500 adet, süs ve tıbbi aromatik bitki yetiştiriciliği için açık alan üst sınırı 2 hektar, sera için üst sınırı 1 hektar olarak belirlenmiştir. Yerel ürün ve mikro işletmelerin geliştirilmesi alt tedbiri iki farklı tedbir gibide düşünülebilir, bu bağlamda yerel ürün olarak, yatırımın yapılacağı ile özgü tarım gıda ürünlerinin üretilmesine yönelik yatırımlar desteklenmektedir örneğin Van ili için otlu peynir üretimi ya da inci kefali tesisi gibi yatırımlar. Mikro işletmelerin geliştirilmesi kapsamında zanaatkârlık işletmeleri desteklenmektedir. Halıcılık, kilimcilik, taş oymacılığg, ahşap işıleri, savatçılık, cam işlemeciliği, yorgancılık, sepet örücülügü gibi yatırımlar tedbir kapsamında tüm IPARD illerinde desteklenmektedir. Kırsal turizm alt tedbiri kapsamında konaklama, yeme içme tesisleri ile rekreasyonel faaliyetler için alanların ve tesislerin kurulması desteklenmektedir. Konaklama tesisleri için 25 yatak odası üst sınır olarak belirlenmiş yeme içme tesisleri ve rekreasyonel faaliyetler için yatırım için sınır sadece alt tedbir için üst limit olarak belirlenen 500000 avro ile sınırlandırılmıştır. Kültür balıkçılığı alt tedbiri kapsamında karada ve kafes yetiştiriciliği şeklinde yıllık kapasitesi 10-200 ton olan yetiştiricilik işletmeleri desteklenmektedir. Desteklenecek türler ise alabalık, sazan, yayın, kerevit, kurbağa ve su yosunu (alg) olarak belirlenmiştir(TKDK 2018c). 


\section{Türkiye'nin IPARD I Programı (2007-2013) Kazanımları}

IPARD I programı süresince çıkılan 15 çağrı sonucunda 101, 103 ve 302 tedbirlerinden toplam 10693 proje ile sözleşme imzalanmıştır. Hayata geçen yatırımların yaklaşık değeri 6.7 milyar TL ve bu yatırımlara TKDK (IPARD) desteği 3.15 milyar TL olarak gerçekleşmiştir. Ayrıca uygun harcamalar için sağlanan vergi muafiyeti ile yatırımcılara 1.18 milyar TL dolaylı katkı sağlanmıştır. Desteklenen yatırımlar sonucunda 57 bin yeni istihdam oluşturulmuştur. Proje başvurusunda bulunan kişi ya da temsilcilerinin kadın ya da genç olmasına öncelik verilmesinden dolayı 40 yaş altı 4572 yatırımcı ve 1055 kadın yatırımcı desteklenmiştir. Program sonucunda AB tarafindan ülkemize tahsis edilen IPARD bütçesinin \%99.52'si yatırımcılar ile buluşturularak önemli bir başarı elde edilmiştir(TKD 2018a).

Çizelge 5. Tedbir Bazlı Destek Miktarları

\begin{tabular}{|c|c|c|c|}
\hline Tedbir & $\begin{array}{l}\text { AB Katk1s1 } \\
\text { (Avro) }\end{array}$ & $\begin{array}{l}\text { Ulusal Katk1 } \\
\text { (Avro) }\end{array}$ & Toplam (Avro) \\
\hline $\begin{array}{lcr}\text { 101-Tarımsal } & \text { İşletmelerin } & \text { Yeniden } \\
\text { Yapılandırılması } & \text { ve } & \text { Topluluk } \\
\text { Standartlarına } & \text { Ulaştırılmasına } & \text { Yönelik } \\
\text { Yatırımlar } & & \end{array}$ & 463031428 & 154343809 & 617375237 \\
\hline 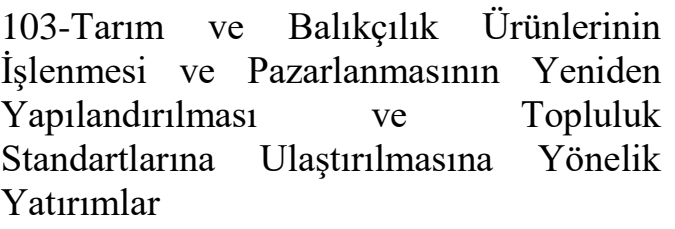 & 184048441 & 61349480 & 245397921 \\
\hline $\begin{array}{l}\text { 302-Kırsal Ekonomik } \\
\text { Çeşitlendirilmesi vaaliyetlerin } \\
\text { Yönelik Yatırımlar }\end{array}$ & 141801121 & 47267040 & 189068162 \\
\hline Teknik Destek ${ }^{*}$ & 752040 & 188010 & 940050 \\
\hline Toplam & 789633030 & 263148339 & 1052781370 \\
\hline
\end{tabular}

*Teknik destek tedbirinin faydalanıcısı Yönetim Otoritesidir(Tarım ve Orman Bakanlığı). 
Çizelge 6. IPARD I Sektör Bazlı Sözleşme, Yatırım ve Hibe Miktarları

\begin{tabular}{|c|c|c|c|c|}
\hline Tedbir Kodu/Ad1 & Alt Tedbir Ad 1 & $\begin{array}{l}\text { Sözleşme } \\
\text { İmzalanan } \\
\text { Proje Sayısı }\end{array}$ & $\begin{array}{c}\text { Toplam } \\
\text { Yatırım } \\
\text { Tutarı } \\
\text { (Milyon TL) }\end{array}$ & $\begin{array}{l}\text { Ödenen Hibe } \\
\text { Tutar1 } \\
\text { (Milyon TL) }\end{array}$ \\
\hline \multirow{4}{*}{$\begin{array}{l}\text { Tedbir 101. Tarımsal } \\
\text { İşletmelerin Yeniden } \\
\text { Yapılandırılması ve } \\
\text { Topluluk Standartlarına } \\
\text { Ulaştırılmasına yönelik } \\
\text { yatırımlar }\end{array}$} & $\begin{array}{l}\text { Süt Üreten } \\
\text { İşletmeler }\end{array}$ & 1107 & 2485 & 1.265 \\
\hline & & 382 & 608 & 290 \\
\hline & 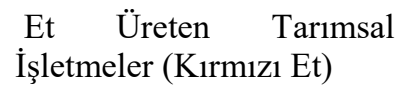 & & & \\
\hline & $\begin{array}{l}\text { Et Üreten Tarımsal } \\
\text { İşletmeler (Kanatll Eti) }\end{array}$ & 731 & 981 & 515 \\
\hline \multirow{6}{*}{$\begin{array}{l}\text { Tedbir 103. Tarım ve } \\
\text { Balıkçılık Ürünlerinin } \\
\text { İşlenmesi } \\
\text { Pazarlanmasının } \\
\text { Yeniden } \\
\text { Yapılandırılması ve } \\
\text { Topluluk Standartlarına } \\
\text { Ulaştırılmasına Yönelik } \\
\text { Yatırımlar }\end{array}$} & $\begin{array}{l}\text { Süt ve Süt Ürünlerinin } \\
\text { İslenmesi ve Pazarlanması }\end{array}$ & 120 & 370 & 157 \\
\hline & Süt Toplam Merkezi & 51 & 23 & 9.9 \\
\hline & $\begin{array}{l}\text { Et ve et Ürünlerinin } \\
\text { İşlenmesi ve Pazarlanması } \\
\text { (Kırmızı et) }\end{array}$ & 92 & 355 & 139 \\
\hline & $\begin{array}{l}\text { Et ve et Ürünlerinin } \\
\text { İslenmesi ve Pazarlanması } \\
\text { (Kanatlı Eti) }\end{array}$ & 21 & 65 & 23 \\
\hline & $\begin{array}{l}\text { Sebze ve Meyvenin } \\
\text { İşlenmesi ve Pazarlanması }\end{array}$ & 141 & 398 & 163 \\
\hline & $\begin{array}{l}\text { Balıkçılık Ürünlerinin } \\
\text { İşlenmesi ve Pazarlanması }\end{array}$ & 19 & 58 & 22 \\
\hline \multirow{3}{*}{$\begin{array}{l}\text { Tedbir 302. Kırsal } \\
\text { Ekonomik Faaliyetlerin } \\
\text { Çeşitlendirilmesi } \\
\text { Geliştirilmesi }\end{array}$} & $\begin{array}{l}\text { 1- Çiftlik Faaliyetlerinin } \\
\text { Çeşitlendirilmesi }\end{array}$ & 7292 & 600 & 276 \\
\hline & 2- Yerel Ürünler ve Mikro & 329 & 303 & 121 \\
\hline & $\begin{array}{l}\text { 3- Kırsal Turizm } \\
\text { 4- Kültür } \quad \text { Balıkçıllığ } \\
\text { (Yetiştiricilik) }\end{array}$ & $\begin{array}{c}360 \\
21\end{array}$ & $\begin{array}{c}393 \\
16\end{array}$ & $\begin{array}{c}154 \\
6\end{array}$ \\
\hline Tedbir 501. Teknik Destek & & 27 & 2.9 & 2.7 \\
\hline Toplam & & 10693 & 6664 & 3147 \\
\hline
\end{tabular}

*Teknik destek tedbirinin faydalanıcısı Yönetim Otoritesidir (Tarım ve Orman Bakanlığı). 


\section{ISSN2777-7238 | ISPEC Juurnal of Agricultural Sciences}

IPARD I Programının (2007-2013) sona ermesi ile IPA için ikinci yedi y1llık program hazırlanmıştır. AB komisyonu tarafından kabul edilen ikinci yedi yıllık program 2014-2020 yıllarını kapsamaktadır. IPA II ile birlikte IPARD II programı da uygulanmaya başlanmıştır. IPARD II kapsamında 101 tedbirine mevcut uygulamalara ek olarak manda eti ve manda sütü üretimi, yumurta tavukçuluğu ve kaz eti üretimi sektörleri eklenmiştir. 103 tedbirine mevcut destekleme alanlarına ek olarak kaz üretimine paralel bir şekilde kaz kesimhaneleri ve parçalama tesisleri eklenmiştir. 302 tedbirinde bazı yapısal değişikliklerin yanında mevcut desteklemelere mantar üretimi, fide fidan üretimi, katma değerli ürünler, makine parkları ve yenilenebilir enerji yatırımları eklenmiştir. Ayrıca eksen 2 olarak tanımlanan ve IPARD I kapsamında desteklenmeyen Yerel Kırsal Kalkınma Stratejilerinin Hazırlanması ve Uygulanması tedbiri desteklenmeye başlanmıştır. Yapılan bu değişikliklere ek olarak 101 tedbiri hibe oran1 \%40-70, 103 tedbiri \%50, 302 tedbiri \%55-65 ve 202 tedbiri $\% 100$ olacak şekilde düzenlenmiştir (TKDK 2018c).

\section{SONUÇ}

Program kapsamında desteklenen projeler incelendiğinde proje sayısı bakımından 302-Kırsal Ekonomik Faaliyetlerin Çeşitlendirilmesi ve Geliştirilmesine Yönelik Yatırımlar tedbirine ait sözleşmelerin diğer tedbirlere göre çok yüksek olduğu görülmektedir. Bu durum proje başlıkları incelendiğinde arıcılık, tıbbi aromatik bitki yetiştiriciliği gibi düşük bütçeli ve nispeten daha rahat uygulanabilir projeler olması nedeniyle beklenen bir durumdur. Kullanılan fon bakımından tedbirler incelendiğinde Tedbir 101. Tarımsal İşletmelerin Yeniden Yapılandırılması ve Topluluk Standartlarına Ulaştırılmasına yönelik yatırımlar tedbiri diğer tedbirlere oranla çok daha fazladır. Ülkemizin hayvancılık potansiyeli ve mevcut işletmelerin hayvan refahı gibi $\mathrm{AB}$ standartlarından uzak olduğu bilinen bir durumdur. Kurumun bu destekleriyle mevcut işletmelerin modernize edilmesi ayrıca AB standartlarına sahip yeni işletmelerin kurulması ve tahsis edilen bütçenin bu tedbirde daha yüksek olması en fazla fon kullanan alanın oluşması sonucunu doğurmuştur.

AB'ye üyelik sürecinin ağır aksak ilerlemesine, dönem dönem iplerin tamamen atılmasının gündeme gelmesine rağmen 2007 yılında kurulan bir kurumun personel alımı, çalışma ortamı için fiziki şartları oluşturma ve AB' den yetki devri gibi uzun soluklu süreci 3,5 yıllık bir sürede kat etmiş olması önemli bir başarı olarak değerlendirilmektedir. Ayrıca bu kadar genç bir kurumun $\mathrm{AB}$ standartlarını sağlayan işletmeler için finans desteğinde bulunması ve $\mathrm{AB}$ standartlarını ülke şartlarına uyumlu hale getirmesi ayrı bir başarı olarak ele alınmaktadır. Yedi Year 3/ 2019, Volume-3, Issue-1 | https://ispecjournal.com 


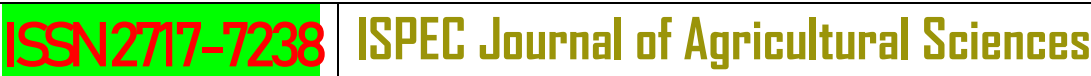

y1llık olarak hazırlanan ve her y1l için belli bir bütçenin tahsis edildiği bir programda kullanılamayan fonun aday ülke için yanma riskinin bulunmasına karşın IPARD için ayrılan bütçenin \%99.52'sinin kullanılmış olması çok önemlidir.

IPARD I programına tahsis edilen bütçenin tüm handikaplara rağmen (TKDK'nın yeni bir kurum olması, yetki devrinin program başladıktan sonra alınmış olması ve ilk uygulama olması gibi) neredeyse tamamı kullanılmıştır. Bu performansa ek olarak kurumun deneyim kazanması, yeni sektörlerin desteklenmeye başlanması ile potansiyel başvurucu yelpazesinin genişlemesi ve ülkede IPARD ve TKDK destekleri hakkında farkındalık kazanılmış olması IPARD II programının daha başarılı olacağını göstermektedir.

TKDK, kırsal kalkınma fonlarının dağıtılmasında Avrupa Birliği üye ve aday ülkelerinde kullanılmakta olan proje bazlı fon dağıtımı ve kullanılan fonların yerindelik ve uygunluğunun etkin bir şekilde izlenmesi bağlamında önemli bir kurumsal tecrübe ortaya koymaktadır. Yalnızca Avrupa Birliği ile ilişkiler çerçevesindeki faaliyetler için değil, kamu kaynaklı sektörel destek ve kredilerin de dağıtılmasında kurumun sahip olduğu bilgi ve deneyim model olarak ele alınabileceği düşünülmektedir. Bu zeminde fon dağıtımının performansı sonuçları ve bu analizlerin TKDK'nın yurtdışındaki muadili kuruluşlarla mukayesesi sonraki araştırmaların konusunu teşkil etmektedir.

\section{KAYNAKÇA}

Anonim, (2018). Türkiye- AB mali iş birliği. https://www.ab.gov.tr/5.html. Erişim tarihi: 18.12.2018.

Bilici, İ. (2010). Türkiye’ de Kırsal Kalkınmanın Gelişimi ve IPARD Süreci, Gaziosmanpaşa Üniversitesi Fen Bilimleri Enstitüsü, Yayınlanmamış Yüksek Lisans Tezi, Tokat.

Demirkıran, Ö. Çiçek, E. Eltetik, H. \& Sarıkçıŏlu, M. (2010). Türkiye-Avrupa Birliği İlişkilerinde" Son Dönem". Niğde Üniversitesi İİBF Dergisi, 2010, Cilt:3, Sayı:1, s.57-75.

Kösecik, M. \& Yıldırım, F. (2001). “AB’nin Yerel Yönetimler Üzerindeki Etkileri”, Türk İdare Dergisi, S.431, Haziran 2001.

Özcan, A. B. (2011). Uluslararası Güvenlik Sorunları Ve Abd'nin Güvenlik Stratejileri. Sosyal Ekonomik Araştırmalar Dergisi, 11(22), 445-466.

Özer, M. A. (2007). Temel Belgeler Eşliğinde Türkiye-Avrupa Birliği İlişkileri. Sayıştay Dergisi, 66(67), 67-98.

TKDK. (2018a). Stratejik plan 2017-2021. http://www.tkdk.gov.tr/Kurumsal/StratejikPlan. Erişim tarihi: 18.12 .2018 . 


\section{ISSN2717-7238 ISPEC Jaurnal of Agricultural Sciences}

TKDK. (2018b). Başvuru çağrı ilanları http://www.tkdk.gov.tr/ProjeIslemleri/CagriIlanArsiv. Erişim tarihi: 18.12 .2018$.

TKDK. (2018c). IPARD Programı. http://www.tkdk.gov.tr/Ipard/IpardProgrami. Erişim tarihi: 18.12.2018.

Toprak, H. (2010). Mali Yardım Aracı (IPA) ve Türkiye-Avrupa Birliği Mali Yardım İlişkileri. Yayımlanmamış Yüksek Lisans Tezi, Gazi Üniversitesi SBE. 